$\xi=$ 줄

\title{
A massive growth at atypical location- a rare case report
}

\author{
Harshita Garg ${ }^{1 *}$, Gouri Bhatia ${ }^{2}$, Ritika A Kapoor ${ }^{2}$, Shivi Khattri ${ }^{2}$ \\ ${ }^{1}$ Postgraduate student Department of Periodontology Subharti Dental College and Hospital, NH-58, \\ Subhartipuram, Delhi-Haridwar Bypass Road Meerut \\ ${ }^{2}$ Department of Periodontology Subharti Dental College and Hospital, NH-58, Subhartipuram, \\ Delhi-Haridwar bypass road Meerut \\ *Corresponding author E-mail: drharshi1518@gmail.com
}

\begin{abstract}
Idiopathic fibrous hyperplasia is one of the most common lesions of all oral fibrous tumor like growths. It is a benign neoplasm and usually associated with local irritation. Its presence at unique location makes it even more interesting to study and understand. A 30 -year-old systemically healthy male patient presented to the Department of Periodontics with the chief complaint of swelling in an unusual location on the hard palate. Clinically, the swelling was firm, solitary and pedunculated. Radiographs displayed no hard tissue involvement. Treatment comprised of combined approach using both electrosurgery and scalpel. Thus, it can be concluded that fibromas of the oral soft tissues include a diverse group of reactive and neoplastic conditions. Therefore, lot of expertise and knowledge is required for proper diagnosis and treatment planning.
\end{abstract}

Keywords: Fibroma; Hard Palate; Swelling

\section{Introduction}

Fibrous hyperplasia synonymous with Focal fibrous hyperplasia (FFH), irritational or traumatic fibroma (Santos et al. 2014) is a rare benign neoplastic proliferation of fibrous connective tissue. It is a nonspecific reactive lesion of soft tissues usually associated with local irritation. The proposed etiological factors that may be associated with the lesion are genetic predisposition or alteration, viruses, carcinogens, immunological and nutritional elements (chillies, spicy food, tobacco, vitamin B deficiency, etc) (Lorenzo et al. 2010). It is the most common soft tissue growth in the oral cavity because oral mucosa is constantly subjected to external and internal stimuli and thus manifesting spectrum of diseases (Effiom et al. 2011).

The most common intraoral site is along the occlusal line of the buccal mucosa but it also affects lower lip, tongue, edentulous alveolar ridge and hard palate (Gonsalves et al. 2007). It can be either generalised or localised wherein the generalised form has a genetic predisposition and could recur after surgery (Palaia 2013). This report describes a case of idiopathic fibrous hyperplasia, its management and differential diagnosis.

\section{Case presentation}

A 30 year-old male patient reported to the Department of Periodontics with the chief complaint of swelling, that is, the centre of the posterior region of hard palate and difficulty in chewing and swallowing (figure-1). History revealed that swelling was noticed around 19 years back when he was at the age of 11 years. Swelling was smaller initially and became progressively larger thus increasing difficulty in swallowing. The patient was otherwise systemically healthy and his medical and dental history was not contributory.
Extra-oral examination showed no significant abnormality. On intraoral examination, inspection revealed a well- circumscribed $3 \mathrm{~cm} \times 4 \mathrm{~cm}$ pale-pink, symmetric, peduculated growth located on the mid palatal line at the junction of hard and soft palate (figure$2 a, 2 b)$. The swelling was painless and covered by the normal mucosa. On palpation, lesion was non tender, firm in consistency, non-fluctuant and non-compressible.

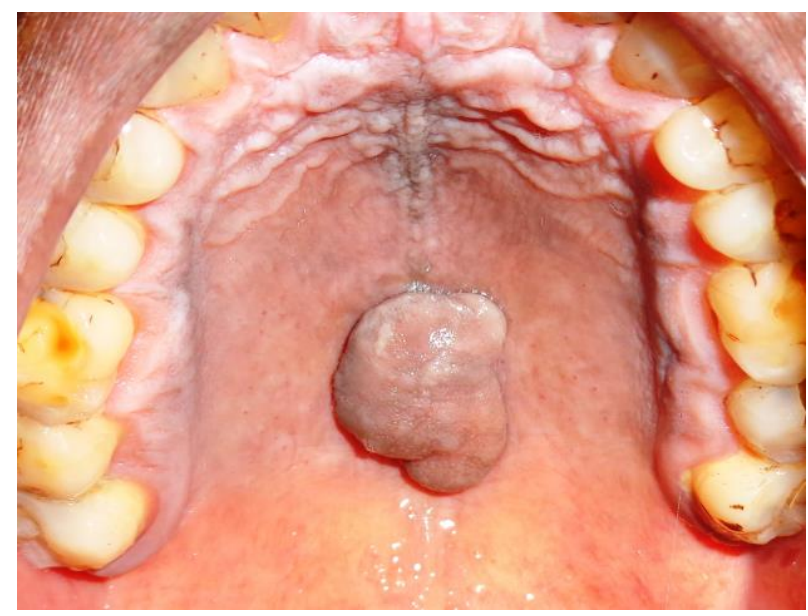

Fig.1: Intraoral Preoperative view

\section{Procedure}

An informed consent was obtained from the patient prior to treatment. Investigations included a complete hemogram, Occlusal radiograph (figure-3) and CBCT (Cone Beam Computed Tomography) before treatment to rule out any possible bony involvement (figure-4).Oral hygiene instructions were given and scaling and 
polishing were done on the first visit. Then, the patient was recalled for surgical excision of the lesion after 7 days.

After administration of local anaesthesia, the lesion was excised from its base using Bard Parker blade no. 15. The roughened margins were contoured and hemostasis was achieved with electrosurgery. The excised lesion was then transferred to $10 \%$ formalin and sent to the Department of Oral Pathology for histopathological examination (figure-5). A removable Hawley's appliance (acrylic stent) with periodontal dressing was given to the patient for the protection of surgical wound and to avoid trauma at the operated area. The patient was advised to maintain oral hygiene and was asked to rinse his mouth with $0.2 \%$ chlorhexidine mouthwash twice daily for a week. The patient was kept under observation through recall check-ups.
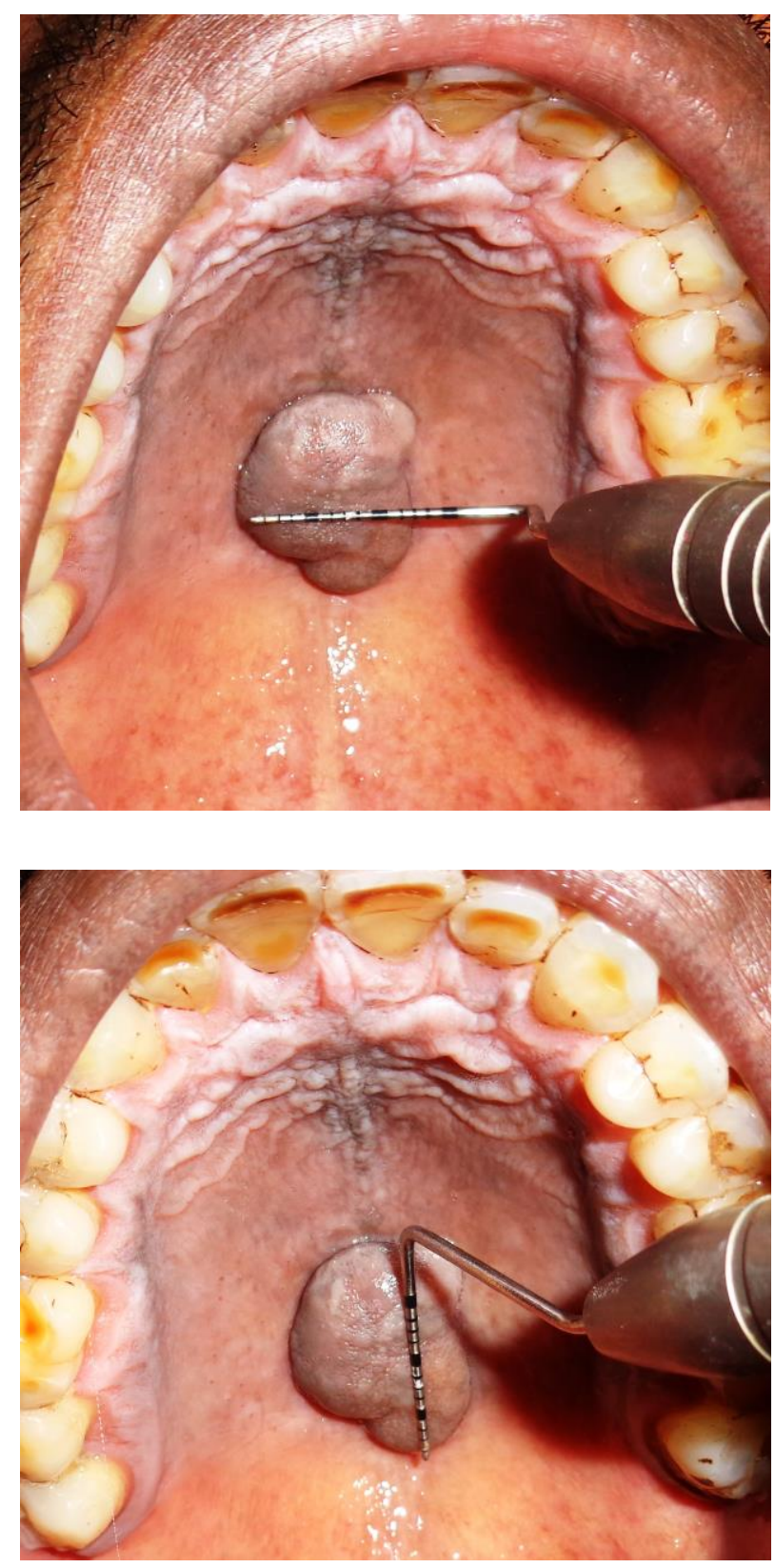

Fig.2a and 2b: A well circumscribed $3 \mathrm{~cm} \times 4 \mathrm{~cm}$ symmetrical growth on posterior aspect of mid-palatal line

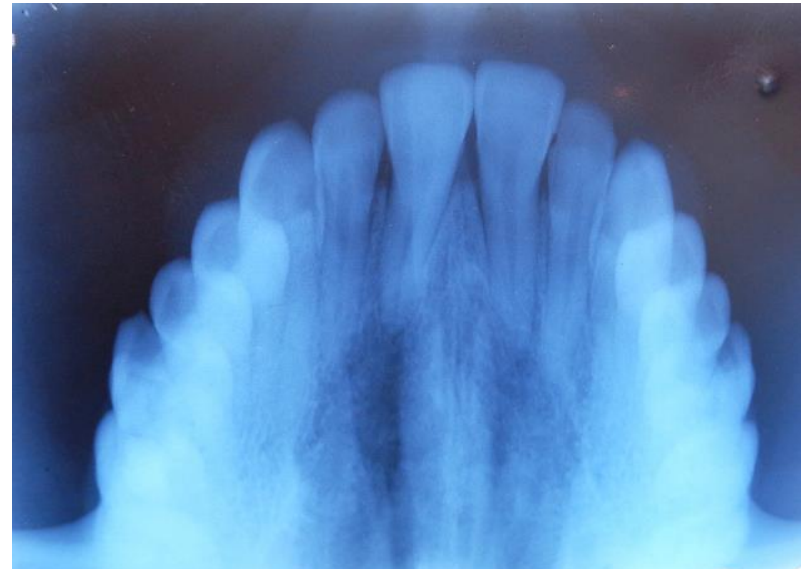

Fig.3: Occlusal radiograph revealing no hard tissue involvement.

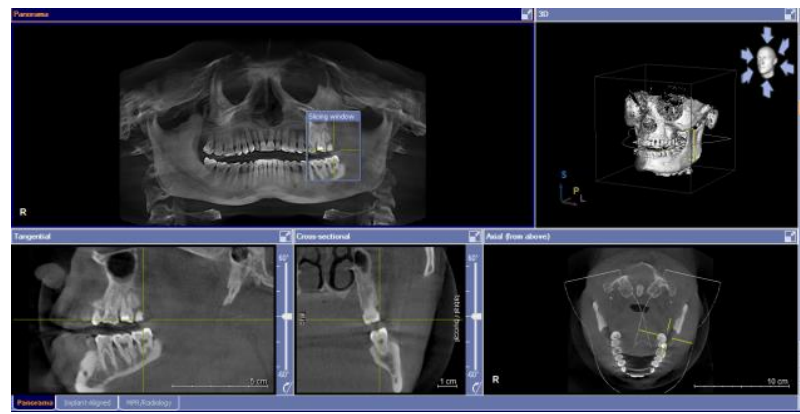

Fig. 4: Pre-operative CBCT scan

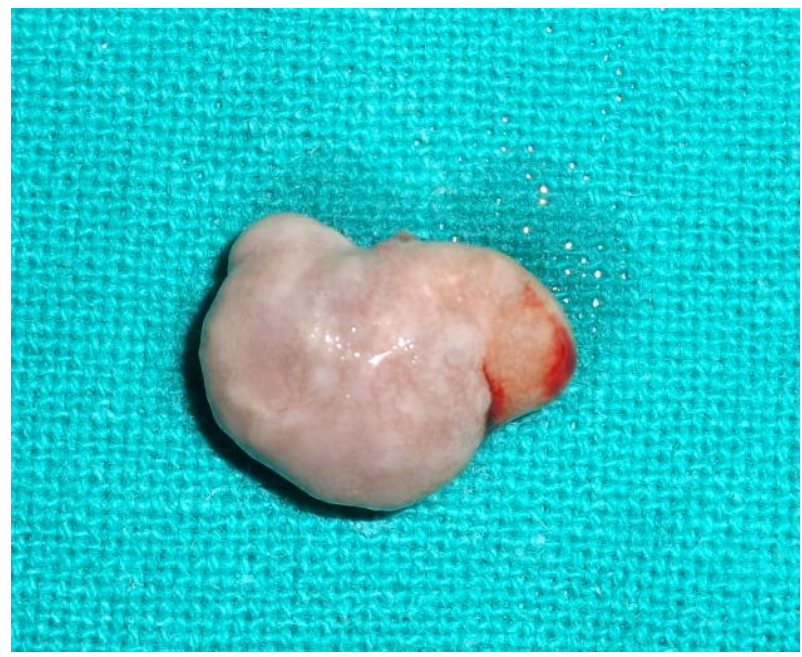

Fig. 5: Excised lesion

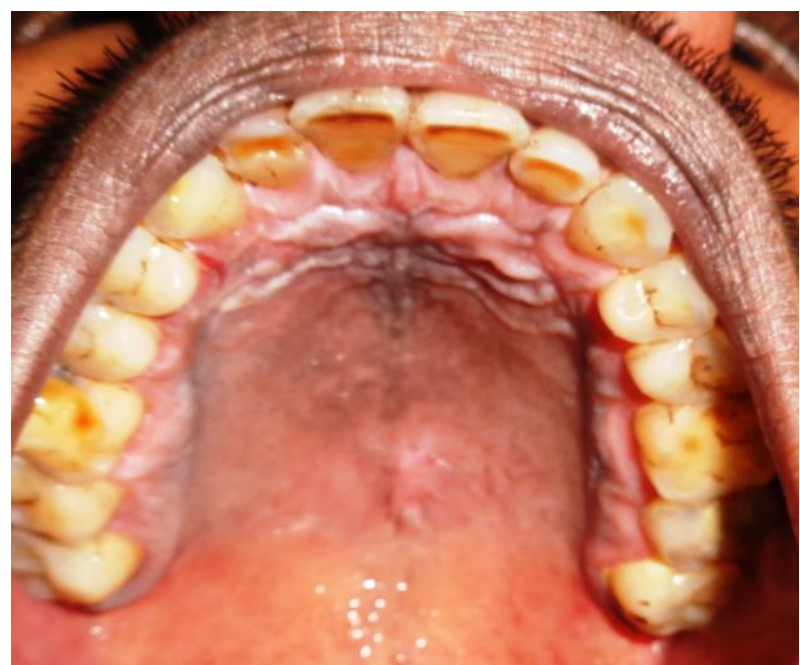

Fig. 6: One-week post-operative view. 


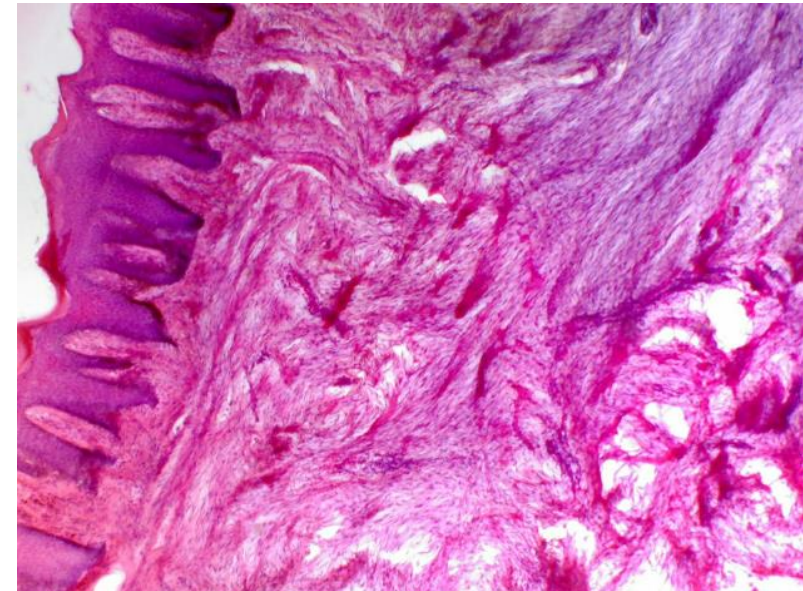

Fig. 7: Histopathologic picture illustrating hyalinised fibrous connective tissue with elongated rete ridges suggesting idiopathic fibrous hyperplasia.

\section{Clinical outcomes}

Healing was uneventful with no bleeding or pain observed during or after the surgery. At 7 days complete tissue recovery was seen. Histological examination revealed dense, hyalinised fibrous connective tissue often arranged in haphazard fascicles. The surface epithelium appeared hyperkeratotic and ulcerated, thus confirming the clinical diagnosis of Idiopathic Fibrous Hyperplasia (figure-7). The patient was recalled after 6 months and no recurrence of the growth was seen (figure-6).

\section{Discussion}

The term inflammatory hyperplasia is used to describe a large range of commonly occurring nodular growths that are localised, reactive and involve progressive proliferation of the oral mucosa. Clinically it appears as a submucous hard, deeply firm and solitary swelling (Jafarzadeh et al. 2006).

The lesion can affect people of all ages and both genders but it is more common in $3^{\text {rd }}, 4^{\text {th }}$ and $5^{\text {th }}$ decade of life with two times more predilection for females than males and only $1.2 \%$ of them are seen affecting the hard palate (Gonsalves et al. 2007, Mathur et al. 2010). In the present case, the massive lesion was seen at the junction of hard and soft palate which is quite unusual.

Fibrous hyperplasia exhibits a limited growth potential, which is a determining factor for the absence of superficial ulcerations due to secondary trauma.

Radiographic investigations were done to further diagnose the disease. Occlusal radiograph was done to detect if there is any bony involvement and advanced imaging i.e. Cone beam computed tomography (CBCT) was also done but it did not reveal any significant involvement of hard tissue.

Differential diagnosis of fibrous hyperplasia include a true fibroma (Praetorius-Clausen 1972), pyogenic granuloma (PG), peripheral giant-cell granuloma (PGCG) and peripheral ossifying fibroma (POF) (Daley et al. 1990). Thus, definitive diagnosis was done based on histological analysis to rule out the possibility of lesions that may have a similar appearance.

Although they all are also strongly associated with the chronic local irritation and trauma, their histological aspects are different especially when the lesions have a short duration.

However, histological picture of fibrous hyperplasia showed orthokeratinised stratified squamous epithelium with underlying fibrous connective tissue stroma. This stroma showed dense bundles of collagen fibres, fibroblasts and blood capillaries.

Other differential diagnosis should include giant cell fibroma, neurofibroma, mucocele and benign and malignant salivary gland tumour (Devishree et al. 2010).

Though various treatment modalities are there for the excision of the lesion like scalpel, laser, electro-surgery. In the present case, scalpel technique and electro-surgery was used as this combined approach helps to utilize the benefits of both techniques. Convention scalpel technique involves the risk of surgery like bleeding and poor patient compliance. On the other hand, electro-surgery has a better efficacy, safety of the procedure, mild bleeding and the absence of postoperative complication (Devishree et al. 2010).

\section{References}

[1] Santos TS, Filho PR, Piva MR, Andrade ES (2014) Focal fibrous hyperplasia: A review of 193 cases. J Oral Maxillofac Pathol. 18(1):86-9. http://dx.doi.org/10.4103/0973-029X.141328.

[2] Lorenzo S, Milia A, Corradino B, Cordova A (2010) uncommon case of symmetrical fibrous hyperplasia of the hard palate. Eur Rev Med Pharmacol Sci 14:145-146.

[3] Effiom OA, Adeyemo WL, Soyele OO (2011) Focal reactive lesions of the gingival: An analysis of 314 cases at tertiary health institution in Nigeria. Niger Med J. 52:35-40.

[4] Gonsalves WC, Chi AC, Neville BW (2007) Common oral lesions: Part II. Masses and neoplasia. Am Fam Physician. 75:509-12.

[5] Palaia G (2013) Idiopathic fibrous hyperplasia of the palate. Annals of stomatology 4(2):35.

[6] Jafarzadeh H, Sanatkhani M, Mohtasham N (2006). Oral pyogenic granuloma: a review. J Oral Sci 48(4), 167-75. http://dx.doi.org/10.2334/josnusd.48.167.

[7] Mathur LM, Bhalodi AP, Manohar B, Bhatia A, Rai N, Mathur A (2010) Focal fibrous hyperplasia: A Case Report. Int J Dent Clinics 2(4):56-7.

[8] Praetorius-Clausen F (1972). Rare oral viral disorders molluscum contagiosum, localized keratoacanthoma, verrucae, condylomaacuminatum, and focal epithelial hyperplasia. Oral Surg, Oral Med, Oral Pathol 34(4):604-18. http://dx.doi.org/10.1016/00304220(72)90344-1.

[9] Daley T, Wysocki G, Wysocki P, Wysocki D (1990). The major epulides: clinicopathological correlations. J Can Dent Assoc 56(7):627-30.

[10] Devishree, Gujjari SK, Shubhashini PV (2010). Frenectomy: A review with the reports of surgical techniques. J Clin Diagn Res. 6(9):1587-92. 